\title{
Hybrid 3D structure of poly(D,L-lactic acid) loaded with chitosan/chondroitin sulfate nanoparticles to be used as carriers for biomacromolecules in tissue engineering
}

\author{
Vítor E. Santo ${ }^{\mathrm{a}, \mathrm{b}, *}$, Ana Rita C. Duarte ${ }^{\mathrm{a}, \mathrm{b}}$, Manuela E. Gomes ${ }^{\mathrm{a}, \mathrm{b}}$, João F. Mano ${ }^{\mathrm{a}, \mathrm{b}}$, Rui L. Reis ${ }^{\mathrm{a}, \mathrm{b}}$

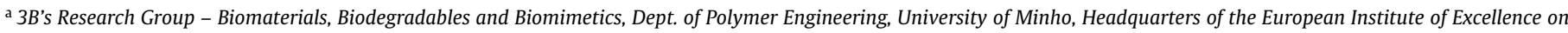 \\ Tissue Engineering and Regenerative Medicine, AvePark, Zona Industrial da Gandra, S. Cláudio do Barco, 4806-909 Caldas das Taipas, Guimarães, Portugal ${ }^{1}$ \\ ${ }^{\mathrm{b}}$ IBB - Institute for Biotechnology and Bioengineering, PT Associated Laboratory (Laboratório Associado), Portugal ${ }^{2}$
}

\section{A R T I C L E I N F O}

\section{Article history:}

Received 11 February 2010

Received in revised form 24 May 2010

Accepted 24 May 2010

\section{Keywords:}

Supercritical fluid foaming

Poly(D,L-lactic acid)

Scaffolds

Tissue engineering

Chitosan

Chondroitin sulfate

Controlled release

\begin{abstract}
A B S T R A C T
In the tissue engineering (TE) field, the concept of producing multifunctional scaffolds, capable not only of acting as templates for cell transplantation but also of delivering bioactive agents in a controlled manner, is an emerging strategy aimed to enhance tissue regeneration. In this work, a complex hybrid release system consisting in a three-dimensional (3D) structure based on poly(D,L-lactic acid) (PDLLA) impregnated with chitosan/chondroitin sulfate nanoparticles (NPs) was developed. The scaffolds were prepared by supercritical fluid foaming at 200 bar and $35^{\circ} \mathrm{C}$, and were then characterized by scanning electron microscopy (SEM) and micro-CT. SEM also allowed to assess the distribution of the NPs within the structure, showing that the particles could be found in different areas of the scaffold, indicating a homogeneous distribution within the 3D structure. Water uptake and weight loss measurements were also carried out and the results obtained demonstrated that weight loss was not significantly enhanced although the entrapment of the NPs in the 3D structure clearly enhances the swelling of the structure. Moreover, the hybrid porous biomaterial displayed adequate mechanical properties for cell adhesion and support. The possibility of using this scaffold as a multifunctional material was further evaluated by the incorporation of a model protein, bovine serum albumin (BSA), either directly into the PDLLA foam or in the NPs that were eventually included in the scaffold. The obtained results show that it is possible to achieve different release kinetics, suggesting that this system is a promising candidate for dual protein delivery system for TE applications.
\end{abstract}

(c) 2010 Elsevier B.V. All rights reserved.

\section{Introduction}

In tissue engineering (TE), a porous scaffold is typically required to act as a template for cell proliferation, differentiation and cell growth. Scaffolds may also act as controlled release devices that deliver growth factors (GFs) with rates matching the physiological need of the regenerating tissue. The process of new tissue formation may be augmented by the delivery of bioactive factors (e.g. GFs) that induce cells to behave in a specific manner [1]. The aim of targeted drug delivery is to selectively deliver drugs/bioactive agents to spe-

\footnotetext{
* Corresponding author at: 3B's Research Group - Biomaterials, Biodegradables and Biomimetics, Dept. of Polymer Engineering, University of Minho, Headquarters of the European Institute of Excellence on Tissue Engineering and Regenerative Medicine, AvePark, Zona Industrial da Gandra, S. Cláudio do Barco, 4806-909 Caldas das Taipas, Guimarães, Portugal.

E-mail address: v.espirito.santo@dep.uminho.pt (V.E. Santo).

1 http://www.3bs.uminho.pt.

2 www.ibb.pt.
}

cific sites and to release them locally in order to induce a desired response of the target tissue, without affecting the surrounding tissues. Recently some studies [2-5] have reported the incorporation of drug or protein-loaded particles into TE scaffolds to form composites with the ability of delivering bioactive molecules that aid in tissue regeneration [6]. Ideally, the concept of delivering bioactive agents directly from the polymer matrix which is used as a template for cell transplanting is an attractive approach. However, the major challenge in developing drug delivery systems is to incorporate such biologically active guest species, without loss or change of activity, into a polymeric host. In the case of proteins, the major challenges in developing protein-encapsulated systems are [7,8]: (i) instability of encapsulated proteins; (ii) their incomplete release, and (iii) initial burst release. One of the major advantages of a sustained delivery approach is the possible reduction in the required cumulative dose, which is an advantage in order to avoid supraphysiological levels of proteins and to reduce the cost of the therapy [9]. Tissue morphogenesis and regeneration are typically driven by concomitant action of multiple factors, which can work 
synergistically on the same process, or can target different barriers to regeneration [10]. Temporal and spatial control of the release of such factors is crucial to a successful tissue repair and regeneration [11].

In this work, we propose a novel hybrid scaffold composed of a poly(D,L-lactic acid) (PDLLA) porous scaffold incorporating chitosan/chondroitin sulfate $(\mathrm{CH} / \mathrm{CS}$ ) nanoparticles (NPs) for ultimate application on the TE field.

PDLLA is a well known biodegradable material because of its excellent mechanical strength [12-14] and it has been commonly used for fabricating biocompatible and porous scaffolds $[13,15,16]$. However, PDLLA is a hydrophobic material that retards the diffusion of water molecules into its matrix, and so it takes a long time to degrade [12]. Common scaffold fabrication techniques include solvent casting/salt leaching [17], moulding/salt leaching [18], and gas foaming/salt leaching [19]. These conventional methods require the use of organic solvents and/or high processing temperatures, which can prohibit their use in the preparation of GF-loaded scaffolds. Additionally, some of the mentioned techniques might lead to the loss of fractions of the entrapped GF and also be harmful for cells and nearby tissues [20]. In order to overcome these limitations, carbon dioxide $\left(\mathrm{CO}_{2}\right)$ has been used as a plasticizer and foaming agent to form three-dimensional (3D) scaffolds [15]. Remarkable progress has been made in the application of dense gases to the processing of polymers over the last decade. Gas foaming technology [21], crosslinking reactions at high pressure $\mathrm{CO}_{2}$ [22] and supercritical $\mathrm{CO}_{2}$-water emulsion techniques [23] have been used to fabricate porous hydrogels or scaffolds from different kinds of polymers [24]. $\mathrm{CO}_{2}$ is inexpensive, non-toxic and non-flammable and readily available in high purity from a variety of sources. Supercritical carbon dioxide $\left(\mathrm{scCO}_{2}\right)$ combines gas-like diffusivity with the liquid-like density, which makes it a unique medium for polymer synthesis and processing [15,22,24].

However, despite the obvious advantages, this technique presents some clear limitations. The control over internal scaffold architecture cannot approach that of, for instance, the 3D printing technique. Also the range of polymer types for which supercritical fluids (SCFs) are applicable might be limiting in some applications, particularly where high mechanical strength is required [11]. The ability to plasticize polymers at close to $37^{\circ} \mathrm{C}$ and the inherently low solubility of proteins in $\mathrm{scCO}_{2}$ provides a key processing advantage; thermal and solvent labile species can be processed easily whilst preserving protein structure and function $[11,25]$.

Richardson et al. [26] also applied the gas foaming/salt leaching approach for the simultaneous encapsulation of two angiogenic GFs - vascular endothelial growth factor (VEGF) and platelet derived growth factor (PDGF) - in poly(lactide-co-glycolide) (PLG) foams for dual release, with tailored release profiles. In this case, PDGF was pre-encapsulated in PLG microspheres while VEGF was dispersed in an alginate powder, generating the different kinetics. The dual delivery of these two GFs promoted the formation of a vascular network in vivo to a greater extent than either of the two GF delivered alone [26]. The drawback of this strategy is the use of salt leaching step, which removes some of the incorporated bioactive material [11].

Several reports [1,27-36] have shown that SCF technology seems appropriate for the development of appropriate architectures for TE applications, with the inclusion of the biological cues for further stimulation of cell behaviour and enhancement of tissue regeneration. Some other studies [2-4,10,37-40] have already addressed the application of dual release systems for TE purposes. Encouraging resul1ts have been obtained in the enhancement of bone and cartilage regeneration, as well as improved vascularisation.

To our knowledge, no works have been published on the entrapment of NPs into polymeric sponges by gas foaming procedure.
Chen et al. [41] reported the microencapsulation of pueranin NPs by PLA. In our study, $\mathrm{CH} / \mathrm{CS}$ NPs previously developed in our group [42], which have shown to be able to release proteins in a controlled manner, were entrapped in the PDLLA foam. Bovine serum albumin (BSA) was used as model protein to assess the entrapment and in vitro release kinetics, in order to study the potential application of this PDLLA-NPs hybrid structure for dual protein release with distinct kinetics. The protein dispersed in the PDLLA polymer should be released at a faster pace, while the protein entrapped in the NPs should be delivered in slower fashion.

\section{Experimental procedure}

\subsection{Materials}

Low molecular weight (116 kDa) chitosan ( $\mathrm{CH})$ (448869), chondroitin sulfate (CS) (C9819), bovine serum albumin (BSA/A2153, pI 5.3), phosphate buffered saline tablets (PBS), Dulbecco's modified Eagle's medium low glucose, Dulbecco's modified Eagle's medium without phenol red and sodium bicarbonate were purchased from Sigma Aldrich (Germany). Fetal bovine serum (FBS) was purchased from Biochrom AG (Germany) and antibiotic-antimycotic (A/B) solution from Gibco (Spain). (3-(4,5-dimethylthiazol-2-yl)-5-(3carboxymethoxyphenyl)-2-(4-sulfophenyl)-2H-tetrazolium) MTS reagent was purchased from Promega (UK). Chitosan was further purified by the precipitation procedure [43], all the other chemicals were used with no further purification. After $\mathrm{CH}$ purification, the final deacetylation degree was 75-85\%. PDLLA with an inherent viscosity of $1.87 \mathrm{dL} / \mathrm{g}$ was purchased from Purasorb. Carbon dioxide ( $99.998 \mathrm{~mol} \%$ ) was supplied by Air Liquide. MicroBCA protein detection kit was purchased from Pierce.

\subsection{Preparation of the nanoparticles}

Chitosan/chondroitin sulfate nanoparticles (CH/CS NPs) were prepared as described previously by Santo et al. [42]. Briefly, $\mathrm{CH}$ was dissolved in $1 \%(\mathrm{w} / \mathrm{v})$ acetic acid while $\mathrm{CS}$ was dissolved in distilled water at room temperature, to obtain solutions of $6 \mathrm{mg} / \mathrm{mL}$ and $0.81-0.94 \mathrm{mg} / \mathrm{mL}$, respectively, in order to reach final theoretical $\mathrm{CH} / \mathrm{CS}$ ratio of $1 / 1(\mathrm{w} / \mathrm{w})$. The NPs suspension spontaneously occurred when the $\mathrm{CH}$ solution was added to the $\mathrm{CS}$ solution, under strong magnetic stirring at room temperature. To prepare the protein-loaded CH/CS NPs, BSA (pI 5.3) was dissolved in water and further mixed in the CS solution afterwards. Following a $10 \mathrm{~min}$ centrifugation at $11,500 \times g$, the supernatants were discarded and the NPs were isolated. The protein concentrations used for this study were such that allowed the preparation of NPs with $15 \%$ $(\mathrm{w} / \mathrm{w})$ of protein respective to the NP content.

\subsection{Supercritical fluid foaming}

The scaffolds were prepared by SCF foaming at 200 bar and $35^{\circ} \mathrm{C}$ in a high pressure equipment especially designed for this purpose. In each experiment ca. $100 \mathrm{mg}$ of PDLLA was loaded in a mould, which was placed inside the high pressure vessel. The vessel was heated in by means of an electric thin band heater (OGDEN, USA) connected to a temperature controller, which maintained the temperature within $\pm 1^{\circ} \mathrm{C}$. Carbon dioxide was pumped into the vessel using a high pressure piston pump (P-200A Thar Technologies) until the operational pressure was attained. The pressure inside the vessel was measured with a pressure transducer. The system was closed for $30 \mathrm{~min}$ to allow the plasticization of the polymer. Afterwards the system was slowly depressurized (ca. $5 \mathrm{bar} / \mathrm{min}$ ).

When BSA and/or the NPs were loaded in the 3D construct, they were previously suspended in ethanol and afterwards added to the 
PDLLA powder in the mould. The SCF foaming procedure was the same as the above described.

\subsection{Scaffold characterization}

Scanning electron microscopy (SEM): samples of the scaffolds prepared were observed under a scanning electron microscope (Leica Cambridge, Model S360, UK). The matrices were cut after being frozen with liquid nitrogen and coated with gold palladium using a sputter coater (JEOL JFC-1100).

Micro-computed tomography $(\mu-\mathrm{CT})$ : The inner structure, porosity and interconnectivity were evaluated by microcomputerized tomography using a micro-CT scanner (Skyscan 1702 , Belgium) with penetrative X-rays of $40 \mathrm{keV}$. The X-ray scans were acquired in high-resolution mode. CT Analyser ${ }^{\circledR}$ software was used to visualize and reconstruct the 2D X-ray sections images of the scaffolds.

\subsection{Water uptake and degradation}

The swelling capability of the prepared matrices was assessed by measuring the water uptake of the samples for a period up to 21 days. Pre-weighed scaffolds, prepared by SCF foaming, were immersed in $10 \mathrm{~mL}$ of $\mathrm{PBS}$ at $\mathrm{pH}=7.4$. The samples were placed in a water bath at $37^{\circ} \mathrm{C}$. After predetermined periods of time $(1,3$, 7,14 and 21 days) the samples were weighed in order to determine the water uptake of the scaffolds.

Water uptake was determined using the following equation:

$\%$ water uptake $=\frac{w_{w}-w_{d}}{w_{d}} \times 100$

where $w_{w}$ is the weight of the wet sample and $w_{d}$ is the weight of the dry sample.

After each time period the samples were dried and weighed to determine the weight loss, which was calculated according to the equation:

\%weight loss $=\frac{w_{w}-w_{i}}{w_{i}} \times 100$

where $w_{f}$ is the weight of the dry sample after immersion and $w_{i}$ is the initial weight of the sample.

The $\mathrm{pH}$ of each solution was also measured in order to follow the release of acidic degradation products into the medium.

The data presented is the result of the average of at least three measurements.

\subsection{Mechanical properties}

Compressive mechanical properties of the scaffolds prepared were measured using an INSTRON 5543 (Instron Int. Ltd., High Wycombe, UK) universal testing machine with a load cell of $1 \mathrm{kN}$. Test samples were obtained by cutting the scaffolds into a cylindrical shape with $8 \mathrm{~mm}$ diameter and $8 \mathrm{~mm}$ height. Compression testing was carried out at a crosshead of $2 \mathrm{~mm} / \mathrm{min}$, until obtaining a maximum reduction in samples height of $60 \%$. The compressive modulus is defined as the initial slope on the stress/strain curves. The data presented is the result of the average of at least three measurements.

\subsection{Protein release studies}

In vitro release studies of BSA from PDLLA foams and PDLLA-NPs hybrid structures were performed by incubating the proteinloaded materials in $5 \mathrm{~mL}$ of PBS, at pH 7.4 under horizontal shaking at $37^{\circ} \mathrm{C}$. The release was performed in sink conditions. At appropriate time intervals, aliquots of $1 \mathrm{~mL}$ were withdrawn and fresh volume of PBS was added to the suspension to replace the sample. The samples were quantified by the microBCA protein detection kit and the optical density was read at $562 \mathrm{~nm}$, on a multiwell microplate reader (Synergy HT, Bio-Tek Instruments, USA). The results were presented as an average of three measurements. BSA was loaded either directly to the PDLLA foam or into the NPs, which were then foamed together with the polymer. When the BSA was loaded directly into the scaffold, 200 and $500 \mu \mathrm{g}$ were entrapped in the 3D structure, both for the PDLLA-only scaffold and for the PDLLA-NPs hybrid structure.

\subsection{Cytotoxicity screening studies}

In order to assess the eventual cytotoxicity of the scaffolds, extracts of the materials were prepared and placed in contact with a mouse fibroblast-like cell line (L929 cells; ECACC, UK) and tested using a MTS assay in accordance to ISO/EN 1099317. Cells were cultured in basic medium composed of Dulbecco's modified Eagle's medium (DMEM) with phenol red and supplemented with $10 \%$ foetal bovine serum and $1 \%$ antibiotic/antimycotic solution. A diluted cell suspension with a concentration of $4 \times 10^{3}$ cells $\mathrm{mL}^{-1}$ was prepared, seeded onto 96 -well plates and incubated for $24 \mathrm{~h}$. The extracts prepared in culture medium were then added to the wells. L929 cells viability was determined for each extract and compared to latex extracts, used as a positive control of cell death. After $72 \mathrm{~h}$ of incubation MTS (3-(4,5-dimethylthiazol-2-yl)-5-(3-carboxymethoxyphenyl)2-(4-sulfophenyl)-2H-tetrazolium) test was performed to assess cellular viability of L929 cells in contact with extracts. The optical density (OD) was read at $490 \mathrm{~nm}$, on a multiwell microplate reader (Synergy HT, Bio-Tek Instruments, USA). All cytotoxicity screening tests were performed using 3 replicates.

\section{Results and discussion}

The concept of TE has long pass the idea of constructing an inert matrix to serve merely as support for cells and tissue growth in the defect site. Instead the use of the scaffold as an active structure to help tissue regeneration is the main target of future therapeutics. In this context, the delivery of biomacromolecules, able to signal and direct tissue growth, is of major importance. In this work we evaluated the possibility of developing a novel hybrid 3D matrix using the SCF technology. PDLLA foams were successfully prepared at $200 \mathrm{bar}$ and $35^{\circ} \mathrm{C}$. The pore size and structure of the PDLLA porous scaffolds produced using $\mathrm{scCO}_{2}$ can be tailored by the modification of the processing conditions. The applied foaming conditions were selected after the work of Tai and coworkers [15]. The selected temperature is close to the physiological temperature and it limits the denaturation of the incorporated biomacromolecules. Moreover, PDLLA shows negligible solubility in $\mathrm{ScCO}_{2}$ under the conditions used in this study [15]. Conway et al. [44] has reported that the solubilisation of even low molecular weight PDLLA requires extreme conditions.

The novelty of the developed system arises from the incorporation of $\mathrm{CH} / \mathrm{CS}$ NPs, which may enhance the potential of this system to act as a dual drug delivery carrier. These NPs result from complexation between two naturally-derived, oppositely-charged polymers, which are of especial interest due to their biological and chemical similarities to natural tissues $[45,46]$. This system is also particularly suited for protein entrapment as CS is one of the most important glycosaminoglycans (GAGs). In nature, the protection and regulation of GFs is provided through their interactions with biopolymers in the extracellular matrix (ECM), such as proteins and polysaccharides [47-49]. One of the groups of these molecules are the proteoglycans, which contain polysaccharides belonging to the 

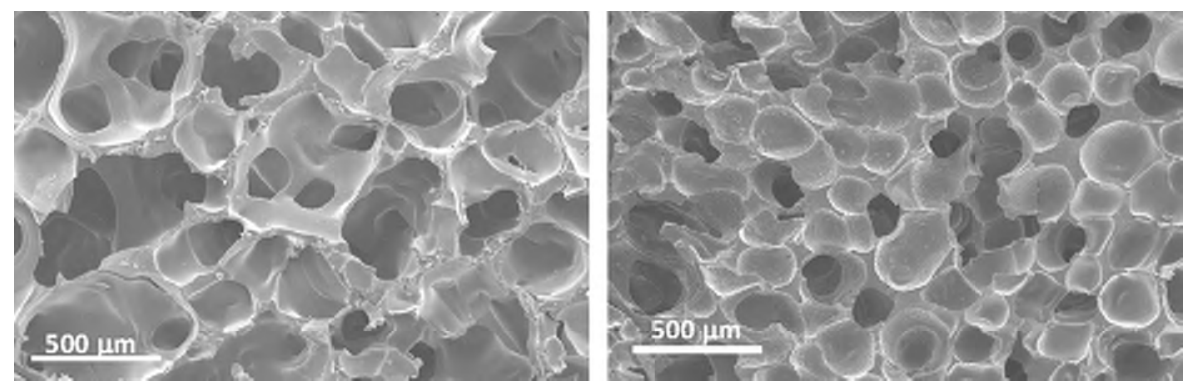

Fig. 1. 3D structures prepared by SCF foaming at 200 bar and $35^{\circ} \mathrm{C}$ : (a) PDLLA and (b) PDLLA loaded with NPs.

family of GAGs. The storage of GFs in the ECM allows for a better localization, regulation, and sustainment of GFs' action as compared to the respective factor in solution that would quickly diffuse out of its location or lose its potency [47,50,51].

These NPs have been developed in a previous work [42] which has demonstrated the suitability of these systems for the controlled release of proteins. The NPs present a spherical shape and size ranging from 150 to $200 \mathrm{~nm}$, as observed by atomic force microscopy and dynamic light scattering (data not shown), with a normal size distribution.

The SEM images of the cross-sections of the scaffolds prepared (Fig. 1) demonstrate the similar morphology of the matrices in the presence or absence of NPs. Both formulations (Fig. 1(a), (b)) displayed random and interconnected morphological organization and for the scaffold foamed with the NPs, there is a homogeneous distribution of the $\mathrm{CH} / \mathrm{CS}$ complex all over the 3D support.

The morphology of the porous structures of 3D scaffolds, namely their porosity, interconnectivity and pore size diameter, is particularly important for the application of such materials in TE and regenerative medicine strategies. Open pores, interconnectivity and adequate pore size for cell growth and vascularisation are key requirements for this purpose. Therefore the developed systems were further characterized using $\mu$-CT (Table 1). Micro-CT allows also a more objective comparison since the porosity and interconnectivity of the samples can be calculated. The interconnectivity of the scaffold is calculated according to the formula: $I=\left[\left(V_{\text {total pore }}-V_{\text {disconnected pore }}\right) / V_{\text {total pore }}\right] \times 100$, where the volume of the disconnected pore stands for the disconnected pore volume which was defined to be higher than $50 \mu \mathrm{m}$. Fig. 2 represents a 2D image of the PDLLA scaffolds. Furthermore, a 3D reconstruction of the matrices is also presented.

The homogeneity of the matrices prepared is confirmed by the Gaussian pore size distribution, which was observed for both PDLLA and NPs-loaded PDLLA scaffolds. A high surface area/volume ratio
Table 1

Summary of the morphological properties of the scaffolds, obtained by $\mu$-CT analysis.

\begin{tabular}{lll}
\hline & PDLLA & NPs-loaded PDLLA \\
\hline Porosity (\%) & 67 & 56 \\
Interconnectivity (\%) & 55 & 39 \\
\hline
\end{tabular}

is needed to assure the mass transport between cells within the scaffold and the surrounding host tissue [1].

The porosity and interconnectivity values decreased when NPs were integrated in the 3D foamed PDLLA scaffold, which was expected due to the addition of another polymeric source into the matrix. In future work, the influence of these morphological features will be further assessed with cell culture, in order to evaluate if the decrease in these parameters might or not significantly affect cell proliferation and metabolism.

\subsection{Mechanical properties}

Mechanical properties of both PDLLA and PDLLA loaded with NPs were evaluated through compression tests as the microstructural characteristics of the scaffold may influence its mechanical properties. Fig. 3 shows, as an example, a representative curve for the deformation behaviour of the porous constructs.

Usually, stress-strain curves for an open cellular material, in compression, present a linear elastic regime, a plateau and a densification regime [52-54]. Beyond the linear region in the stress/strain plot, a permanent deformation will occur, pores will start to collapse and the structure is irreversibly damaged. The compressive modulus was calculated from the initial slope of the curve and it was found to be $12.1 \pm 1.9 \mathrm{MPa}$ and $11.3 \pm 5.6 \mathrm{MPa}$ for PDLLA and NPs-loaded PDLLA scaffolds, respectively. In general, this material presents adequate mechanical properties to support new tissue
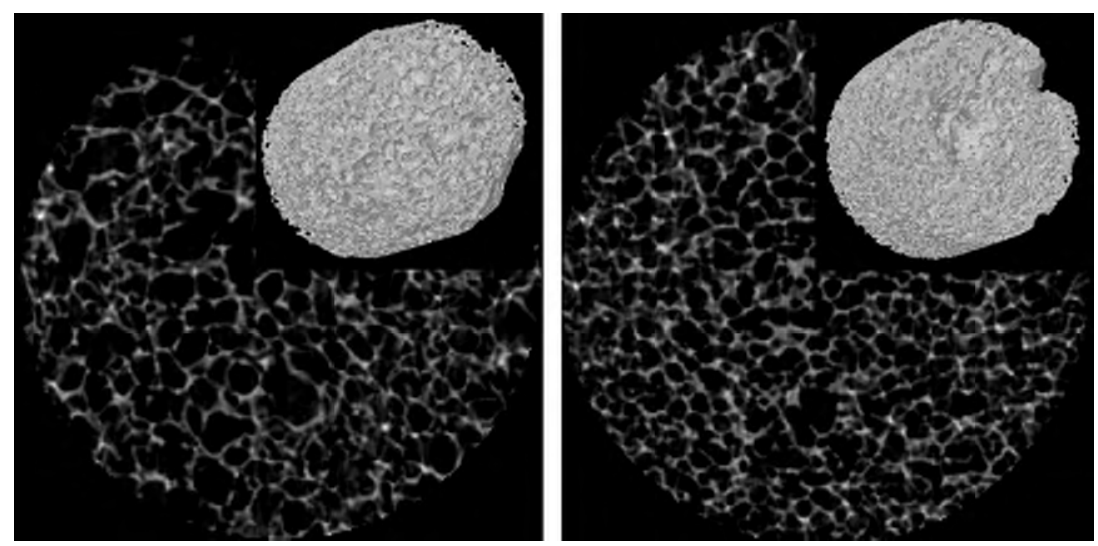

Fig. 2. Representative micro-CT images of the 2D surface and 3D model (a) PDLLA matrices and (b) NPs-loaded PDLLA matrices. 


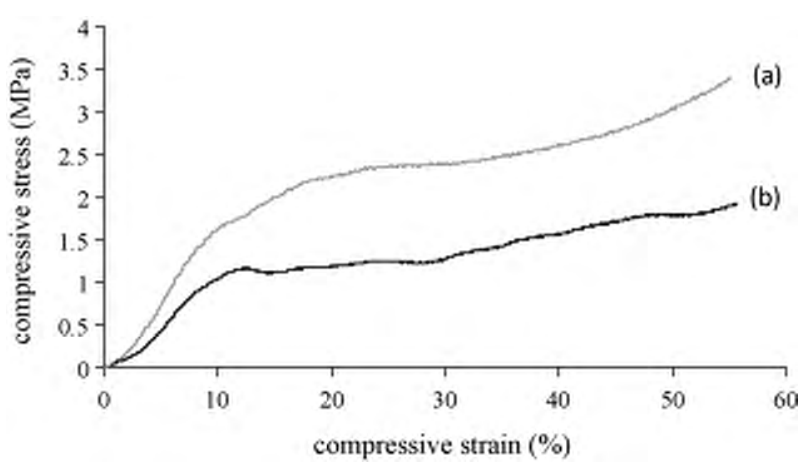

Fig. 3. Representative stress deformation curve of PDLLA scaffolds loaded with NPs (a) and PDLLA scaffolds only (b) prepared at $35^{\circ} \mathrm{C}$ and 200 bar.

growth, which has also been demonstrated in different studies reported in the literature $[53,55]$.

\subsection{Water uptake and degradation studies}

The knowledge of both water uptake and weight loss of the materials prepared is important to study their degradation behaviour since they are aimed to be used in biomedical applications, particularly following a drug delivery strategy. Furthermore, their life time will be governed by these two processes which are intimately correlated.

Water uptake of the porous structures prepared by SCF foaming was evaluated for different time periods for samples immersed in PBS solution. Fig. 4 presents the percentage of water uptake of the matrices as a function of time.

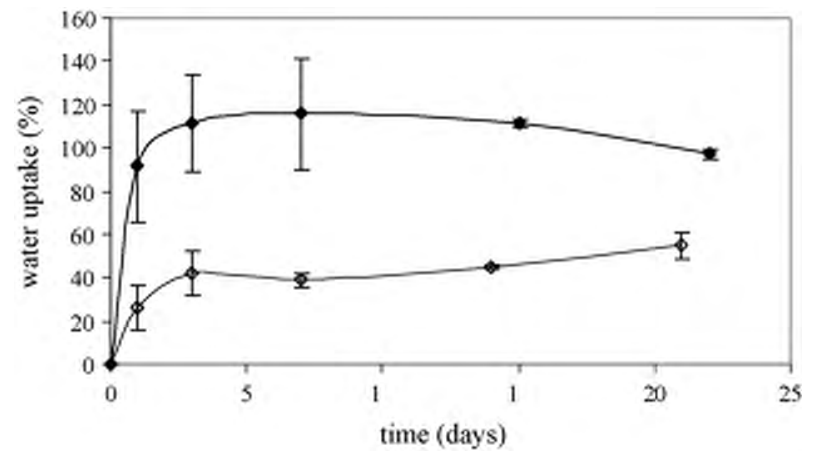

Fig. 4. Water uptake profile of the scaffolds prepared by SCF foaming ( $\diamond)$ PDLLA and (৬) PDLLA loaded with NPs.

The presence of $\mathrm{CH} / \mathrm{CS}$ NPs dispersed in the scaffold greatly changes the hydrophylicity of the matrix as it can be observed in Fig. 4. PDLLA is a hydrophobic synthetic polymer which takes up more than 6 months to degrade and therefore slowly releases entrapped proteins [30]. The addition of hydrophilic polymers has been suggested in previous works [56,57], in order to increase the water uptake and degradation rate of the polymers, and consequently enhancing the protein release rate. In this case, the incorporation of the hydrophilic NPs has the described effect over the water uptake measurements.

Although PDLLA is a widely studied and quite used polymer for biomedical applications, its major drawback is the fact that it can elicit undesirable inflammatory and allergenic reactions $[58,59]$ because of the decrease in the local $\mathrm{pH}$ as a consequence of its hydrolytic degradation. The biodegradation of PDLLA results in the scission of the polymeric chains to monomer units of lactic acid,
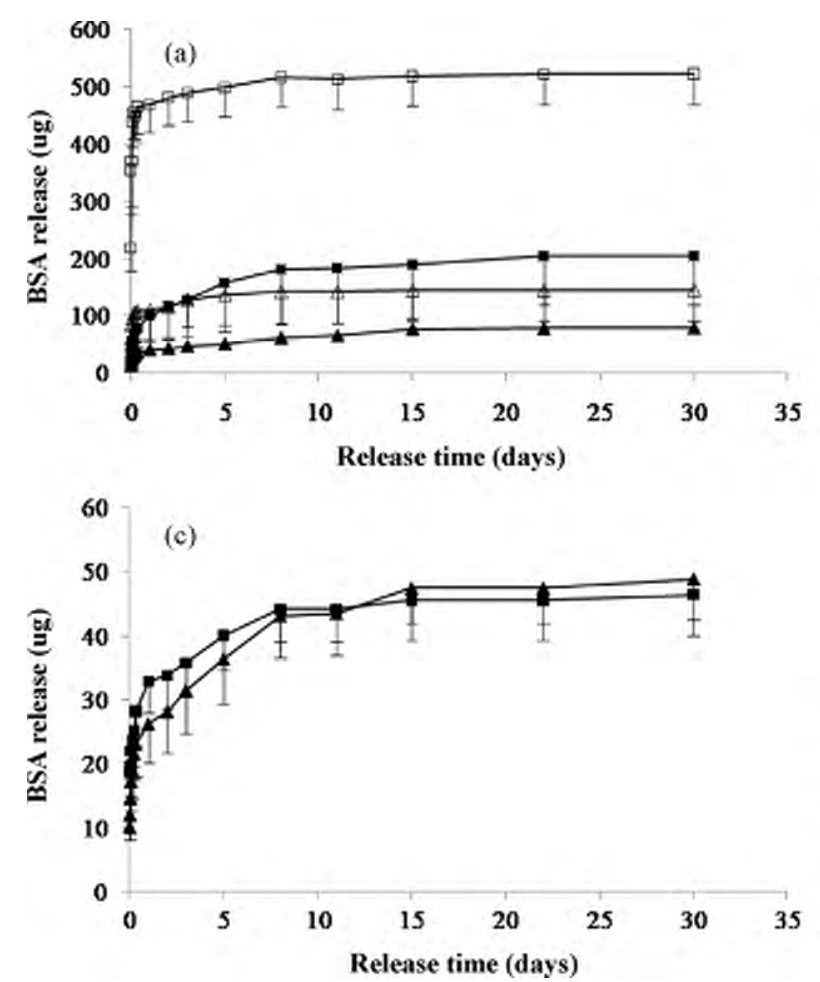

(b)

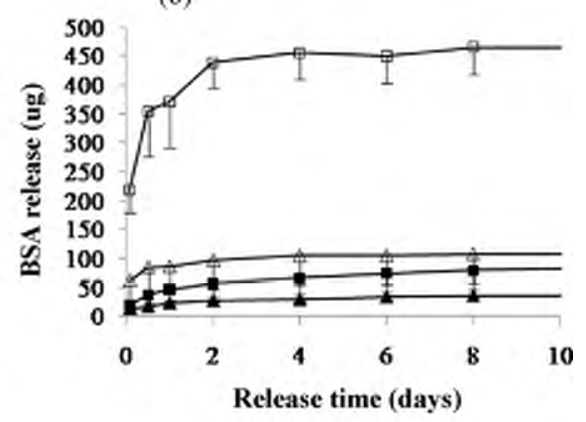

(d)

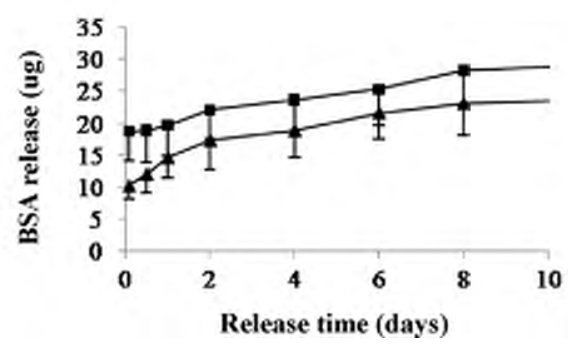

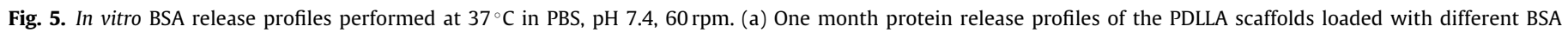

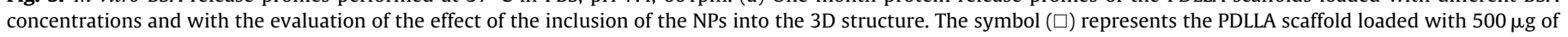

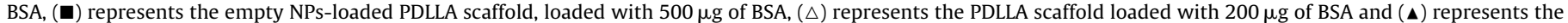

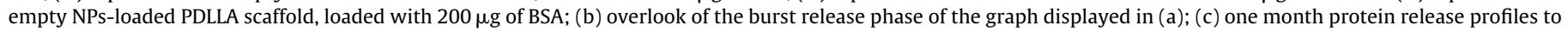

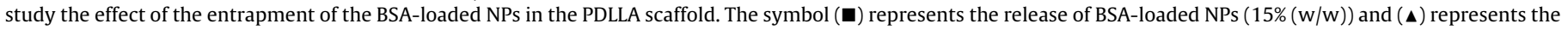
release of the BSA-loaded NPs (15\% (w/w)) entrapped in the PDLLA scaffold; (d) overlook of the burst release phase of the graph displayed in (c). 
as a natural intermediate in carbohydrate metabolism [60]. For this reason, it is important to monitor the $\mathrm{pH}$ of the solution after different periods of immersion. For the studied time period a significant increase in the acidity of the media was not verified (the $\mathrm{pH}$ remained relatively constant, close to the physiological value), neither for the PDLLA scaffolds nor for the scaffolds loaded with the NPs, indicating that the materials suffer a slow hydrolysis degradation process. Furthermore, this is extremely important when aiming to develop a suitable carrier for biomacromolecules which are sensitive to large $\mathrm{pH}$ variations, such as proteins.

Degradation of the scaffolds was followed by weight loss measurements after the predetermined periods of immersion time in PBS and both formulations presented low weight loss values. This was expected as the low rate of degradation of PDLLA has already been reported $[30,61]$. While the PDLLA-only scaffolds lost $3 \%$ of the initial weight in a controlled way, the NPs-loaded PDLLA scaffolds showed a slightly higher weight loss value (6\%) due to the possible leaching of the particles into the medium, nonetheless the degradation process remains very slow. Moreover, the higher water uptake of the scaffolds incorporating the NPs might enhance their hydrolytic degradation.

The incorporation of empty NPs into the PDLLA scaffolds guaranteed a more controlled protein release kinetic when compared with the PDLLA scaffolds alone (Fig. 5(a)). The PDLLA-only foams showed a burst release effect, releasing most of the entrapped BSA during day 1 , for both tested protein loadings -200 and $500 \mu \mathrm{g}$. The initial burst effect is likely due to the delivery of protein bound to the inner pore surfaces of the scaffold, while the subsequent controlled release is likely due to the diffusion of the incorporated BSA. Polymer degradation is not expected to be a mechanism of protein release, since the observed mass loss is not significant $[1,15,30]$. These results demonstrate that during the foaming process, the biggest fraction of the protein remains adsorbed in the 3D PDLLA structure, causing a quick and uncontrolled delivery kinetic.

However, when the $\mathrm{CH} / \mathrm{CS}$ NPs are included in the foaming process, the protein release becomes much more controlled, reducing both the burst effect (Fig. 5(b)) and the delivery rate at a long-term basis. One possible explanation for this phenomenon is the electrostatic interaction between the positively charged NPs and the negatively charged BSA ( $\mathrm{pI}=5.3$ ), resulting in a strong complex and delaying the diffusion of the protein out of the scaffold. Moreover, CS is a sulfated GAG well known for its interaction with proteins and GFs in the ECM, enhancing their action and assuring their stability [47]. This mechanism might be happening too in the PDLLA scaffold, creating strong interactions between CS and BSA.

The development of BSA-loaded $\mathrm{CH} / \mathrm{CS}$ NPs was also performed and the release profile was compared with the BSA-loaded NPs entrapped in the PDLLA foam (Fig. 5(c)). The NPs showed a controlled release profile, delivering the proteins at a constant rate. When the NPs were included in the scaffold, the burst release was slightly reduced (Fig. 5(d)), however not displaying significant differences in a long-term basis. This observation shows that the entrapment of the NPs in the scaffold did not affect the desired controlled release rate of the NPs alone. These findings, together with the improvement on the PDLLA release observed, suggest that it is possible to obtain several different release profiles using this hybrid system, which was our ultimate goal for this work.

The potential use of these materials in biomedical applications demands that they cannot be cytotoxic. Therefore, cytotoxicity assessment of the matrixes leachables was carried out as a very preliminary approach to assess their toxicity potential. Fig. 6 shows the results for the optical density (OD) with the MTS test in order to assess cell viability after $72 \mathrm{~h}$ in contact with the prepared extracts. As it can be observed the leachables of the PDLLA scaffolds and the PDLLA scaffolds loaded with the NPs are not cytotoxic.

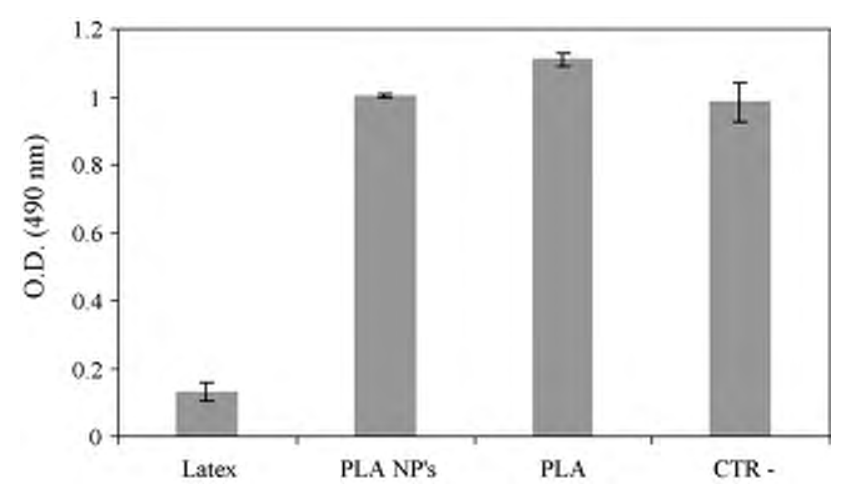

Fig. 6. Cytotoxicity screening of the scaffolds through the extracts test. The assay was performed with the $\mathbf{L} 929$ cell line for 3 days of in vitro culture.

\section{Conclusions}

This work showed the versatility of the SCF foaming procedure, allowing the successful entrapment of polymeric NPs into PDLLA scaffolds, for the ultimate goal of creating a dual release system for applications in the TE field. PDLLA foams were already well described in the literature, however this study has showed that the inclusion of the $\mathrm{CH} / \mathrm{CS}$ NPs did not negatively affect the $3 \mathrm{D}$ structure, maintaining adequate porosity and interconnectivity for cell culture, and displaying adequate mechanical properties. These novel systems are also able to delay the fast and uncontrolled release of proteins loaded directly into the polymeric foam. Moreover, it was possible to design different release profiles, by means of changing the loading parameters of both scaffolds and NPs. The non-cytotoxic behaviour of the PDLLA scaffolds in extraction tests was also not compromised by the inclusion of the $\mathrm{CH} / \mathrm{CS}$ complex in the structure. These results show that this novel hybrid structure composed PDLLA-NPs might be a promising approach as a multifunctional cell template for TE purposes, displaying not only adequate morphological parameters necessary for cell culture but also the ability to deliver bioactive molecules at different rates for further stimulation of cell/tissue behaviour.

\section{Acknowledgments}

Vítor E. Santo and Ana Rita C. Duarte are grateful for financial support from Fundação para a Ciência e Tecnologia (FCT) through the grants SFRH/BD/39486/2007 and SFRH/BPD/34994/2007, respectively. This work was partially supported by the European FP6 Project EXPERTISSUES (NMP3-CT-2004-500283), European FP7 Project Find and Bind (NMP4-SL-2009-229292) and the FCT projects PTDC/FIS/68517/2006 and PTDC/QUI/68804/2006.

\section{References}

[1] W.L. Murphy, M.C. Peters, D.H. Kohn, D.J. Mooney, Sustained release of vascular endothelial growth factor from mineralized poly(lactide-co-glycolide) scaffolds for tissue engineering, Biomaterials 21 (24) (2000) 2521-2527.

[2] Z.S. Patel, S. Young, Y. Tabata, J.A. Jansen, M.E.K. Wong, A.G. Mikos, Dual delivery of an angiogenic and an osteogenic growth factor for bone regeneration in a critical size defect model, Bone 43 (5) (2008) 931-940.

[3] P. Yilgor, K. Tuzlakoglu, R.L. Reis, N. Hasirci, V. Hasirci, Incorporation of a sequential BMP-2/BMP-7 delivery system into chitosan-based scaffolds for bone tissue engineering, Biomaterials 30 (21) (2009) 3551-3559.

[4] D.H.R. Kempen, L.C. Lu, A. Heijink, T.E. Hefferan, L.B. Creemers, A. Maran, M.J. Yaszemski, W.J.A. Dhert, Effect of local sequential VEGF and BMP-2 delivery on ectopic and orthotopic bone regeneration, Biomaterials 30 (14) (2009) 2816-2825.

[5] T.A. Holland, Y. Tabata, A.G. Mikos, Dual growth factor delivery from degradable oligo(poly(ethylene glycol) fumarate) hydrogel scaffolds for cartilage tissue engineering, Journal of Controlled Release 101 (1-3) (2005) 111-125. 
[6] A.A. Weiner, M.C. Moore, A.H. Walker, V.P. Shastri, Modulation of protein release from photocrosslinked networks by gelatin microparticles, International Journal of Pharmaceutics 360 (1-2) (2008) 107-114.

[7] Y. Yeo, K. Park, Control of encapsulation efficiency and initial burst in polymeric microparticle systems, Archives of Pharmacal Research 27 (1) (2004) $1-12$.

[8] J.L. Cleland, A. Daugherty, R. Mrsny, Emerging protein delivery methods, Current Opinion in Biotechnology 12 (2) (2001) 212-219.

[9] S.D. Putney, Encapsulation of proteins for improved delivery, Current Opinion in Chemical Biology 2 (4) (1998) 548-552.

[10] D.M. Salvay, L.D. Shea, Inductive tissue engineering with protein and DNAreleasing scaffolds, Molecular Biosystems 2 (1) (2006) 36-48.

[11] R.A. Quirk, R.M. France, K.M. Shakesheff, S.M. Howdle, Supercritical fluid technologies and tissue engineering scaffolds, Current Opinion in Solid State and Materials Science 8 (3-4) (2004) 313-321.

[12] C.T. Lee, C.P. Huang, Y.D. Lee, Synthesis and characterizations of amphiphilic poly(L-lactide)-grafted chondroitin sulfate copolymer and its application as drug carrier, Biomolecular Engineering 24 (1) (2007) 131-139.

[13] B.J.R.F. Bolland, J.M. Kanczler, P.J. Ginty, S.M. Howdle, K.M. Shakesheff, D.G. Dunlop, R.O.C. Oreffo, The application of human bone marrow stromal cells and poly(DL-lactic acid) as a biological bone graft extender in impaction bone grafting, Biomaterials 29 (22) (2008) 3221-3227.

[14] K. Kim, M. Yu, X.H. Zong, J. Chiu, D.F. Fang, Y.S. Seo, B.S. Hsiao, B. Chu, M. Hadjiargyrou, Control of degradation rate and hydrophilicity in electrospun non-woven poly(D,L-lactide) nanofiber scaffolds for biomedical applications, Biomaterials 24 (27) (2003) 4977-4985.

[15] H. Tai, M.L. Mather, D. Howard, W. Wang, L.J. White, J.A. Crowe, S.P. Morgan, A. Chandra, D.J. Williams, S.M. Howdle, K.M. Shakesheff, Control of pore size and structure of tissue engineering scaffolds produced by supercritical fluid processing, European Cells \& Materials 14 (2007) 64-77.

[16] J.K. Sherwood, S.L. Riley, R. Palazzolo, S.C. Brown, D.C. Monkhouse, M. Coates, L.G. Griffith, L.K. Landeen, A. Ratcliffe, A three-dimensional osteochondral composite scaffold for articular cartilage repair, Biomaterials 23 (24) (2002) 4739-4751.

[17] L. Lu, S.J. Peter, M.D. Lyman, H.L. Lai, S.M. Leite, J.A. Tamada, S. Uyama, J.P. Vacanti, R. Langer, A.G. Mikos, In vitro and in vivo degradation of porous poly(DL-lactic-co-glycolic acid) foams, Biomaterials 21 (18) (2000) 1837-1845.

[18] J.F. Mano, G. Hungerford, J.L.G. Ribelles, Bioactive poly(L-lactic acid)chitosan hybrid scaffolds, Materials Science \& Engineering C-Biomimetic and Supramolecular Systems 28 (8) (2008) 1356-1365.

[19] Y.S. Nam, J.J. Yoon, T.G. Park, A novel fabrication method of macroporous biodegradable polymer scaffolds using gas foaming salt as a porogen additive Journal of Biomedical Materials Research 53 (1) (2000) 1-7.

[20] D.J. Mooney, D.F. Baldwin, N.P. Suh, J.P. Vacanti, R. Langer, Novel approach to fabricate porous sponges of poly(D,L-lactic-Co-glycolic acid) without the use of organic solvents, Biomaterials 17 (14) (1996) 1417-1422.

[21] A. Salerno, D. Guarnieri, M. Iannone, S. Zeppetelli, E. Di Maio, S. Iannace, P.A Netti, Engineered [mu]-bimodal poly([epsilon]-caprolactone) porous scaffold for enhanced hMSC colonization and proliferation, Acta Biomaterialia 5 (4) (2009) 1082-1093.

[22] N. Annabi, S.M. Mithieux, A.S. Weiss, F. Dehghani, The fabrication of elastinbased hydrogels using high pressure $\operatorname{CO}(2)$, Biomaterials 30 (1) (2009) $1-7$.

[23] C. Palocci, A. Barbetta, A. La Grotta, M. Dentini, Porous biomaterials obtained using supercritical $\mathrm{CO}_{2}$-water emulsions, Langmuir 23 (15) (2007) 8243-8251.

[24] A.R.C. Duarte, J.F. Mano, R.L. Reis, Perspectives on: supercritical fluid technology for 3D tissue engineering scaffold applications, Journal of Bioactive and Compatible Polymers 24 (4) (2009) 385-400.

[25] S.M. Howdle, M.S. Watson, M.J. Whitaker, V.K. Popov, M.C. Davies, F.S. Mandel, J.D. Wang, K.M. Shakesheff, Supercritical fluid mixing: preparation of thermally sensitive polymer composites containing bioactive materials, Chemical Communications 01 (2001) 109-110.

[26] T.P. Richardson, M.C. Peters, A.B. Ennett, D.J. Mooney, Polymeric system for dual growth factor delivery, Nature Biotechnology 19 (11) (2001) 1029-1034.

[27] M.H. Sheridan, L.D. Shea, M.C. Peters, D.J. Mooney, Bioadsorbable polymer scaffolds for tissue engineering capable of sustained growth factor delivery, Journal of Controlled Release 64 (1-3) (2000) 91-102.

[28] X.B.B. Yang, M.J. Whitaker, W. Sebald, N. Clarke, S.M. Howdle, K.M. Shakesheff, R.O.C. Oreffo, Human osteoprogenitor bone formation using encapsulated bone morphogenetic protein 2 in porous polymer scaffolds, Tissue Engineering 10 (7-8) (2004) 1037-1045.

[29] D.D. Hile, M.L. Amirpour, A. Akgerman, M.V. Pishko, Active growth factor delivery from poly(D,L-lactide-co-glycolide) foams prepared in supercritical $\mathrm{CO}_{2}$, Journal of Controlled Release 66 (2-3) (2000) 177-185.

[30] P.J. Ginty, J.J.A. Barry, L.J. White, S.M. Howdle, K.M. Shakesheff, Controlling protein release from scaffolds using polymer blends and composites, European Journal of Pharmaceutics and Biopharmaceutics 68 (1) (2008) 82-89.

[31] J.A. Kanczler, P.J. Ginty, J.J.A. Barry, N.M.P. Clarke, S.M. Howdle, K.M. Shakesheff, R.O.C. Oreffo, The effect of mesenchymal populations and vascular endothelial growth factor delivered from biodegradable polymer scaffolds on bone formation, Biomaterials 29 (12) (2008) 1892-1900.

[32] M.J. Whitaker, J.Y. Hao, O.R. Davies, G. Serhatkulu, S. Stolnik-Trenkic, S.M. Howdle, K.M. Shakesheff, The production of protein-loaded microparticles by supercritical fluid enhanced mixing and spraying Journal of Controlled Release $101(1-3)(2005)$ 85-92

[33] A.R.C. Duarte, J.F. Mano, R.L. Reis, Supercritical fluids in biomedical and tissue engineering applications: a review, International Materials Reviews 54 (4) (2009) 214-222

[34] A.R.C. Duarte, S.G. Caridade, J.F. Mano, R.L. Reis, Processing of novel bioactive polymeric matrixes for tissue engineering using supercritical fluid technology, Materials Science \& Engineering C-Materials for Biological Applications 29 (7) (2009) 2110-2115

[35] A.R.C. Duarte,J.F. Mano, R.L. Reis, Preparation of starch-based scaffolds for tissue engineering by supercritical immersion precipitation, Journal of Supercritical Fluids 49 (2) (2009) 279-285.

[36] A.R.C. Duarte, J.F. Mano, R.L. Reis, Dexamethasone-loaded scaffolds prepared by supercritical-assisted phase inversion, Acta Biomaterialia 5 (6) (2009) 2054-2062.

[37] H. Park, J.S. Temenoff, Y. Tabata, A.I. Caplan, R.M. Raphael, J.A. Jansen, A.G. Mikos, Effect of dual growth factor delivery on chondrogenic differentiation of rabbit marrow mesenchymal stem cells encapsulated in injectable hydrogel composites, Journal of Biomedical Materials Research Part A 88A (4)(2009) 889-897.

[38] Y.C. Huang, D. Kaigler, K.G. Rice, P.H. Krebsbach, D.J. Mooney, Combined angiogenic and osteogenic factor delivery enhances bone marrow stromal celldriven bone regeneration, Journal of Bone and Mineral Research 20 (5) (2005) 848-857.

39] C.A. Simmons, E. Alsberg, S. Hsiong, W.J. Kim, D.J. Mooney, Dual growth factor delivery and controlled scaffold degradation enhance in vivo bone formation by transplanted bone marrow stromal cells, Bone 35 (2) (2004) 562-569.

[40] M. Naoki, K. Kenji, H. Motohiro, Y. Hiroshi, T. Yoshinori, O. Hajime, Enhancement of osteoblastic differentiation of mesenchymal stromal cells cultured by selective combination of bone morphogenetic protein-2 (BMP-2) and fibroblast growth factor-2 (FGF-2), Journal of Tissue Engineering and Regenerative Medicine 1 (4) (2007) 306-313.

[41] A.Z. Chen, Y. Li, F.T. Chau, T.Y. Lau, J.Y.Hu, Z. Zhao, D.K.W. Mok, Microencapsulation of puerarin nanoparticles by poly(L-lactide) in a supercritical $\mathrm{CO}_{2}$ process, Acta Biomaterialia 5 (8) (2009) 2913-2919.

[42] V.E. Santo, M.E. Gomes, J.F. Mano, R.L. Reis, Chitosan/chondroitin sulfate nanoparticles for controlled delivery of proteins for application in regenerative medicine, submitted for publication.

[43] J.F Mano, Viscoelastic properties of chitosan with different hydration degrees as studied by dynamic mechanical analysis, Macromolecular Bioscience 8 (1) (2008) 69-76.

[44] S.E. Conway, H.S. Byun, M.A. McHugh, J.D. Wang, F.S. Mandel, Poly(lactide-coglycolide) solution behavior in supercritical $\mathrm{CO}_{2}, \mathrm{CHF}_{3}$, and $\mathrm{CHClF}_{2}$, Journal of Applied Polymer Science 80 (8) (2001) 1155-1161.

45] I.Y Kim, S.J. Seo, H.S. Moon, M.K. Yoo, I.Y. Park, B.C. Kim, C.S. Cho, Chitosan and its derivatives for tissue engineering applications, Biotechnology Advances 26 (1) (2008) 1-21

[46] J.F. Mano, G.A. Silva, H.S. Azevedo, P.B. Malafaya, R.A. Sousa, S.S. Silva, L.F. Boesel, J.M. Oliveira, T.C. Santos, A.P. Marques, N.M. Neves, R.L. Reis, Natural origin biodegradable systems in tissue engineering and regenerative medicine: present status and some moving trends, Journal of the Royal Society Interface 4 (17) (2007) 999-1030.

[47] L. Uebersax, H.P. Merkle, L. Meinel, Biopolymer-based growth factor delivery for tissue repair: from natural concepts to engineered systems, Tissue Engineering Part B-Reviews 15 (3) (2009) 263-289.

[48] Z. Ferdous, K.J. Grande-Allen, Utility and control of proteoglycans in tissue engineering, Tissue Engineering 13 (8) (2007) 1893-1904.

[49] R.J. Linhardt, T. Toida, Role of glycosaminoglycans in cellular communication, Accounts of Chemical Research 37 (7) (2004) 431-438.

[50] J.R. Lieberman, A. Daluiski, T.A. Einhorn, The role of growth factors in the repai of bone-biology and clinical applications, Journal of Bone and Joint SurgeryAmerican 84A (6) (2002) 1032-1044.

[51] A.K.A. Silva, C. Richard, M. Bessodes, D. Scherman, O.W. Merten, Growth factor delivery approaches in hydrogels, Biomacromolecules 10 (1) (2009) 9-18.

52] L. Gibson, M.F. Ashby, The mechanics of 3-dimensional cellular materials, Proceedings of the Royal Society of London Series A-Mathematical Physical and Engineering Sciences 382 (1782) (1982) 43

[53] K.C. Baker, R. Bellair, M. Manitiu, H.N. Herkowitz, R.M. Kannan, Structure and mechanical properties of supercritical carbon dioxide processed porous resorbable polymer constructs, Journal of the Mechanical Behavior of Biomedical Materials 2 (6) (2009) 620-626.

[54] L.J. Gibson, Biomechanics of cellular solids, Journal of Biomechanics 38 (3) (2005) 377-399.

[55] M.M.C.G. Silva, L.A. Cyster, J.J.A. Barry, X.B. Yang, R.O.C. Oreffo, D.M. Grant, C.A Scotchford, S.M. Howdle, K.M. Shakesheff, F.R.A.J. Rose, The effect of anisotropic architecture on cell and tissue infiltration into tissue engineering scaffolds, Biomaterials 27 (35) (2006) 5909-5917.

[56] A.V. Janorkar, A.T. Metters, D.E. Hirt, Modification of poly(lactic acid) films enhanced wettability from surface-confined photografting and increased degradation rate due to an artifact of the photografting process, Macromolecules 37 (24) (2004) 9151-9159.

[57] H.J. Sung, C. Meredith, C. Johnson, Z.S. Galis, The effect of scaffold degradation rate on three-dimensional cell growth and angiogenesis, Biomaterials 25 (26) (2004) 5735-5742. 
[58] X.F. Zhang, H. Hua, X.Y. Shen, Q. Yang, In vitro degradation and biocompatibility of poly(L-lactic acid)/chitosan fiber composites, Polymer 48 (4) (2007) 1005-1011.

[59] H. Li, J. Chang, Preparation and characterization of bioactive and biodegradable Wollastonite/poly(D,L-lactic acid) composite scaffolds, Journal of Materials Science: Materials in Medicine 15 (10) (2004) 1089-1095.
[60] A. Kumari, S.K. Yadav, S.C. Yadav, Biodegradable polymeric nanoparticles based drug delivery systems, Colloids and Surfaces B: Biointerfaces 75 (1) (2010) $1-18$.

[61] L. Wu, J. Ding, In vitro degradation of three-dimensional porous poly(D,Llactide-co-glycolide) scaffolds for tissue engineering, Biomaterials 25 (27) (2004) 5821-5830. 